\title{
BMJ Open Association between malignancies and Marfan syndrome: a population-based, nested case-control study in Taiwan
}

\author{
Chin-Wang Hsu, ${ }^{1,2}$ Jen-Chun Wang, ${ }^{3,4}$ Wen-I Liao, ${ }^{3}$ Wu-Chien Chien, ${ }^{5,6}$ \\ Chi-Hsiang Chung, ${ }^{5,6,7}$ Chang-Huei Tsao, ${ }^{5}$ Yung-Fu Wu, ${ }^{5}$ Min-Tser Liao, ${ }^{8}$ \\ Shih-Hung Tsai ${ }^{3}$
}

To cite: Hsu C-W, Wang J-C, Liao W-I, et al. Association between malignancies and Marfan syndrome: a populationbased, nested case-control study in Taiwan. BMJ Open 2017;7:e017243. doi:10.1136/ bmjopen-2017-017243

- Prepublication history for this paper is available online. To view these files, please visit the journal online (http://dx.doi. org/10.1136/bmjopen-2017017243).

W-CC and S-HT contributed equally.

Received 10 April 2017 Revised 9 September 2017 Accepted 22 September 2017

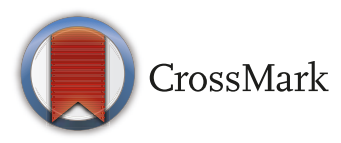

For numbered affiliations see end of article.

Correspondence to Dr. Wu-Chien Chien; chienwu@mail.ndmctsgh.edu. tw and Dr Shih-Hung Tsai; tsaishihung@yahoo.com.tw

\section{ABSTRACT}

Objective Marfan syndrome (MFS) involves a deficiency of the structural extracellular matrix component fibrillin-1 and overactivation of the transforming growth factor- $\beta$ (TGF- $\beta$ ) signalling pathway. The TGF- $\beta$ signalling pathway also actively participates in malignant transformation. Although anecdotal case reports have suggested associations between MFS/MFS-like conditions and several haematological and solid malignancies, such associations have not been thoroughly evaluated in large-scale studies. We sought to use a nationwide healthcare insurance claim database to evaluate whether patients with MFS are at increased risk of malignancy.

Patients and methods We conducted a nested casecontrol analysis using a database extracted from Taiwan's National Health Insurance Research Database. All medical conditions for each case and control were categorised using the International Classification of Diseases, 9th Revision classifications. ORs and $95 \%$ Cls for associations between MFS and malignancies were estimated using conditional logistic regression and adjusted for comorbidities.

Results Our analyses included 1153137 cancer cases and 1153137 propensity score-matched controls. Relative to other subjects, patients with MFS had a significantly higher risk of having a malignancy (adjusted OR 3.991) and hypertension (adjusted OR 1.964) and were significantly more likely to be men. Malignancies originating from the head and neck and the urinary tract were significantly more frequent among patients with MFS than among subjects without MFS.

Conclusion Patients with MFS are at increased risk of developing various malignancies. Healthcare professionals should be aware of this risk when treating such patients, and increased cancer surveillance may be necessary for these patients.

\section{INTRODUCTION}

Marfan syndrome (MFS) is a pleiotropic connective tissue disease caused by a deficiency of the structural extracellular matrix component fibrillin-1 (FBN-1). The study of murine models of MFS has revealed the involvement of the transforming growth factor- $\beta$ (TGF- $\beta$ ) signalling pathway in the

\section{Strengths and limitations of this study}

The associations between Marfan syndrome (MFS)/ MFS-like conditions and malignancies have not been thoroughly evaluated in large-scale studies. Thus, we used a nationwide healthcare insurance claim database to evaluate whether patients with MFS are at increased risk of malignancy. We found that patients with MFS are at increased risk of developing various malignancies.

- The National Health Insurance Research Database registry did not provide detailed information regarding laboratory results, family history and health-related lifestyle factors that could increase the risk of malignancy, and these factors represent potential confounding factors in this study.

- Our study can identify associations between MFS and malignancies, but a case-control study cannot prove a cause-effect relationship.

pathogenesis of this disease. Overactivated TGF- $\beta$ signalling is associated with MFS and several MFS-like conditions, including Loeys-Dietz syndrome, Shprintzen-Goldberg syndrome, aneurysm-osteoarthritis syndrome and syndromic thoracic aortic aneurysm. These conditions are also clearly associated with degenerative non-inflammatory structural cardiovascular diseases, including aortic root dilatation, thoracic aneurysm and aortic dissection. ${ }^{12}$ The TGF- $\beta$ signalling pathway also actively participates in malignant transformation. In tumour cells, TGF- $\beta$ loses its antiproliferative response and becomes an oncogenic factor; as a result, TGF- $\beta$ function is impaired in various solid and haematological malignancies. ${ }^{3}$ TGF- $\beta$-induced epithelial-mesenchymal transition and reversion from mesenchymal to epithelial phenotypes contribute to the survival and dissemination of malignant cells. ${ }^{4}$ Anecdotal case reports have suggested an association between MFS/ MFS-like conditions and several haematological and solid malignancies. ${ }^{5-15}$ However, 
associations between MFS/MFS-like conditions and malignancies have not been thoroughly evaluated in large-scale studies. In this respect, we sought to use a nationwide healthcare insurance claim database to evaluate whether patients with MFS are at increased risk of malignancy.

\section{METHODS}

\section{Data source}

Data for our nationwide, population-based, nested casecontrol study were obtained from inpatient care records and registration files from the Taiwan National Health Insurance Research Database (NHIRD). The National Health Insurance programme was implemented in 1995 and provides healthcare coverage to $99 \%$ of the Taiwanese population (more than 23 million people). The accuracy of the NHIRD with respect to diagnoses for major diseases, such as stroke and acute coronary syndrome, has been validated. ${ }^{16}{ }^{17}$ The confidentiality of individuals was protected by using encrypted personal identification to avoid the possibility of ethical violations related to the study data. This investigation was conducted in accordance with the Declaration of Helsinki and other relevant guidelines. This study was approved by the Institutional Review Board of Tri-Service General Hospital, National Defense Medical Center, Taipei, Taiwan (TSGH IRB number B-104-21).

\section{Cancer cases and controls}

This study involved a nested case-control design. Using the NHIRD, we selected adult patients $>18$ years of age who had been diagnosed with a malignancy based on the International Classification of Diseases, 9th Revision, Clinical Modification (ICD-9-CM) codes (140-208) between 2000 and 2013 and confirmed these patients' diagnoses by linking them to cases registered in the Catastrophic Illness Patient Database. The date of the first malignancy diagnosis was defined as the index date. We identified patients with MFS using the ICD-9-CM code 759.82. A sample of control candidates was selected for comparison from individuals in the NHIRD who were without malignancies. Patients in the study and control groups were selected via 1:1 matching by age, sex, number of medical follow-ups and comorbidities, including hypertension (ICD-9-CM 401-405), diabetes (ICD-9-CM 250), hyperlipidaemia (ICD-9-CM 272.0-272.4), chronic obstructive pulmonary disease (COPD) (ICD-9-CM 490-496), alcoholism (ICD-9-CM 303) and obesity (ICD-9-CM 278). Data on the use of angiotensin-converting enzyme inhibitors and angiotensin receptor blockers were acquired from the Longitudinal Health Insurance Database 2005, a subdatabase of the NHIRD. All insurance claims were scrutinised by medical reimbursement specialists, and peer review was undertaken according to standard and clinical diagnostic criteria, such as the pulmonary function test for COPD. Therefore, the diagnoses of COPD in this study should be highly reliable. Both the NHIRD and catastrophic illness certificate have been well-validated internally and externally in several studies. ${ }^{16} 1819$

\section{Outcome measurements}

Only patients diagnosed with MFS prior to the index date were considered. MFS was identified from the NHIRD by using the corresponding ICD-9 code (ICD-9-CM code 759.82). The following covariates were included: age, gender, hypertension, diabetes mellitus (DM), hyperlipidaemia, COPD, alcoholism and obesity.

\section{Statistical analysis}

Patients' clinical characteristics were expressed in numerical form. Categorical variables, which were presented as percentages, were compared using $\mathrm{X}^{2}$ tests and Fisher's exact test. Continuous variables, which were presented as the mean and SD, were compared using Student's t-tests. The primary goal of this study was to determine whether a patient's clinical characteristics, such as MFS, were associated with malignancies. Associations between those outcomes (prognoses) and clinical characteristics were investigated using conditional logistic regression in a generalised estimating equation (GEE) model. The regression results are presented as adjusted ORs with corresponding 95\% CIs. The threshold for statistical significance was $\mathrm{p}<0.05$. All data analyses were conducted using SPSS V.18 (SPSS).

\section{RESULTS}

A flow diagram of the patient enrolment scheme is presented in figure 1. During the study period, a total of 1153137 patients in follow-up after being diagnosed with a malignancy were identified in the NHIRD, which included a total of 13139306 inpatients. Other patients from the same database who did not have malignancies and were matched by age, gender, number of medical follow-ups and comorbidities were designated controls. As indicated in table 1 , as expected, there were no statistically significant differences between the case and control groups with respect to gender, age, number of medical follow-ups and comorbidities, including hypertension, DM, hyperlipidaemia, COPD, alcoholism and obesity, after matching.

At the end of the 13-year study period, the incidence of MFS was significantly higher among patients with malignancies compared with patients without malignancies over the corresponding observation period $(0.008 \%$ vs $0.003 \%, \mathrm{p}<0.001)$. Among patients with MFS, there were no statistically significant differences regarding the use of angiotensin-converting enzyme inhibitors and angiotensin receptor blockers between patients with or without malignancies (20.93\% vs $21.33 \%$, $\mathrm{p}=0.95 ; 18.60 \%$ vs $19.11 \%, \mathrm{p}=0.93$, respectively). Table 2 indicates that malignancy (adjusted OR 3.991, 95\% CI 2.555 to 6.235, $\mathrm{p}<0.001$ ), maleness (adjusted OR 2.103, 95\% CI 1.427 to 3.098, $\mathrm{p}<0.001$ ) and hypertension (adjusted OR 1.964, 
Inpatient of Health Insurance Database in Taiwan between 2000 and 2013 $(\mathrm{N}=13,139,306)$

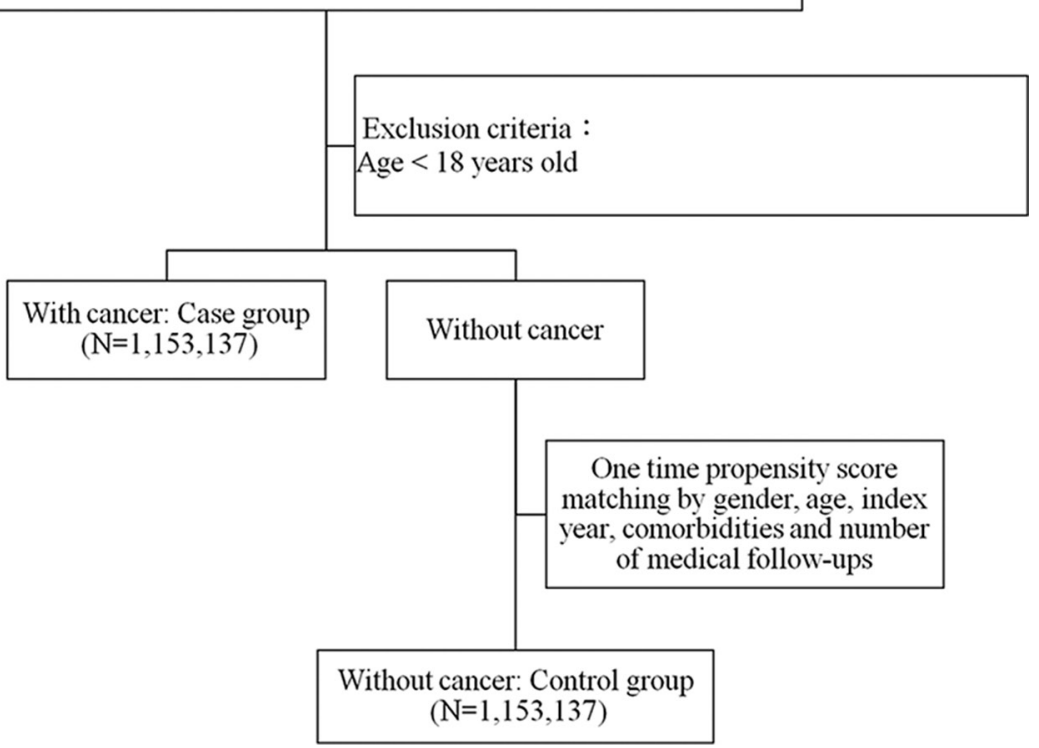

Figure 1 Patient selection flow chart.

95\% CI 1.258 to $3.064, \mathrm{p}=0.013$ ) were significantly associated with patients with MFS.

As indicated in table 3, malignancies originating from the head and neck (adjusted OR 8.714, 95\% CI 2.477 to 30.649, $\mathrm{p}<0.001$ ), oesophagus (adjusted OR 0.970, 95\% CI 3.943 to $30.522, \mathrm{p}<0.001$ ), stomach (adjusted OR 4.639, $95 \%$ CI 1.743 to $12.345, \mathrm{p}=0.002$ ), colon and rectum (adjusted OR 3.134, 95\% CI 1.370 to $7.169, \mathrm{p}=0.007$ ), liver (adjusted OR 3.049, 95\% CI 1.349 to $6.980, \mathrm{p}=0.007$ ), female genital organs (adjusted OR 4.055, 95\% CI 1.417 to $11.606, \mathrm{p}=0.009$ ), prostate (adjusted OR 6.423,
95\% CI 2.355 to $17.517, \mathrm{p}<0.001$ ), urinary tract (adjusted OR $6.478,95 \%$ CI 2.974 to $14.112, \mathrm{p}<0.001$ ) and thyroid (adjusted OR 10.485, 95\% CI 4.251 to 25.861, p<0.001) and haematological malignancies (adjusted OR 6.981, $95 \%$ CI 2.800 to $17.404, \mathrm{p}<0.001$ ) were significantly more frequent among patients with MFS than among subjects without MFS.

As indicated in table 4, patients with MFS acquired malignancies at a younger age than those without MFS. During the study period, patients with MFS had a higher mortality rate and died younger than those without MFS.

Table 1 Baseline characteristics of the study population

\begin{tabular}{llll} 
& $\begin{array}{l}\text { Patients with malignancy } \\
\text { (n=1 153 137) }\end{array}$ & $\begin{array}{l}\text { Patients without malignancy } \\
(\mathbf{n = 1} 153137)\end{array}$ & $\mathbf{p}$ Value \\
\hline MFS & $93(0.008 \%)$ & $27(0.002 \%)$ & 0.999 \\
Gender & & & $657188(56.990 \%)$ \\
Male & $657188(56.990 \%)$ & $495969(43.010 \%)$ & 0.178 \\
Female & $495969(43.010 \%)$ & $63.49 \pm 18.42$ & 0.933 \\
Age (years) & $63.52 \pm 15.21$ & & 0.978 \\
Comorbidities & & $150512(13.052 \%)$ & 0.987 \\
Hypertension & $150555(13.056 \%)$ & $127894(11.091 \%)$ & 0.969 \\
Diabetes & $127884(11.090 \%)$ & $7233(0.627 \%)$ & 0.827 \\
Hyperlipidaemia & $7235(0.627 \%)$ & $48656(4.219 \%)$ & 0.436 \\
COPD & $48668(4.220 \%)$ & $1042(0.090 \%)$ & 0.159 \\
Alcoholism & $1052(0.091 \%)$ & $247(0.021 \%)$ & \\
\hline Obesity & $230(0.020 \%)$ & $4.82 \pm 10.87$ & \\
Medical follow-ups & $4.84 \pm 10.70$ & & \\
\hline
\end{tabular}

COPD, chronic obstructive pulmonary disease; MFS, Marfan syndrome. 
Table 2 Factors of MFS determined using conditional logistic regression in a GEE model

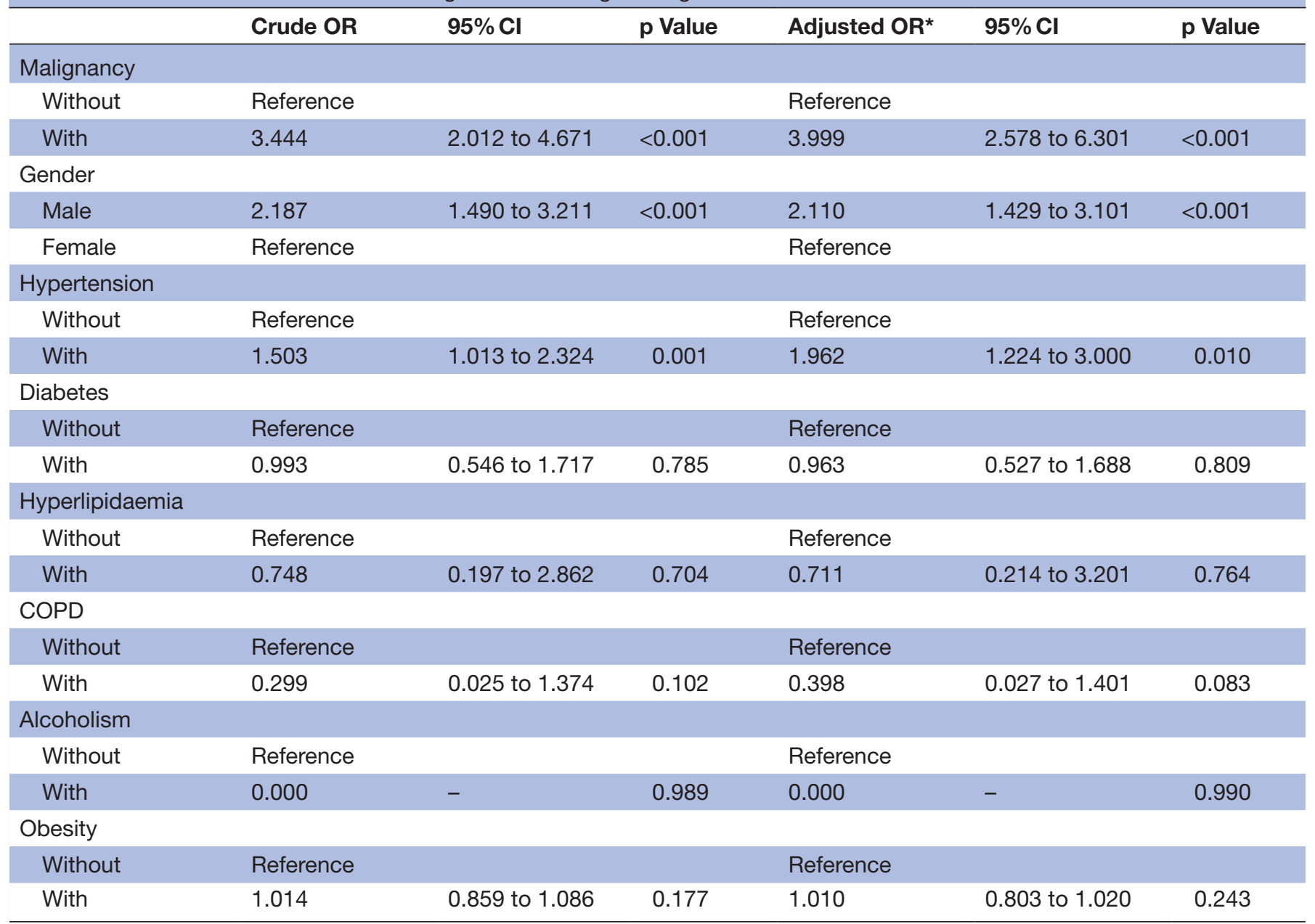

Adjusted by variables listed in the table.

COPD, chronic obstructive pulmonary disease; GEE, generalised estimating equation; MFS, Marfan syndrome.

\section{DISCUSSION}

Using a nationwide population database, we have demonstrated for the first time that MFS is associated with the development of certain malignancies. No systemic approaches have previously been used to elucidate associations between MFS and malignancies.

Numerous case reports have addressed associations between MFS and various solid malignancies, including thyroid cancer, ${ }^{8}$ osteosarcoma, ${ }^{9}$ mesothelioma, ${ }^{14}$ oesophageal cancer, ${ }^{20}$ angiosarcoma, ${ }^{21}$ testicular cancer ${ }^{22}$ and Wilms' tumour. ${ }^{23}$ Multiple endocrine neoplasia syndromes that are characterised by benign and malignant changes in multiple endocrine organs and incidental changes in nervous, muscular and connective tissues can also manifest marfanoid features. ${ }^{24}{ }^{25}$ In our study, we observed that the frequencies of head and neck and urinary tract malignancies were significantly increased in patients with MFS. Accumulated case reports have also indicated that MFS and MFS-like conditions, such as Loeys-Dietz syndrome and Ehlers-Danlos syndrome (EDS), might be associated with various haematological malignancies and non-Hodgkin's lymphoma. ${ }^{5-7} \quad 10-13 \quad 15$ 26-28 Larger, international studies should be conducted to study these potential associations.

As integral components of microfibrils, which provide strength and elasticity to the extracellular matrix, fibrillins, particularly FBN-1 and FBN-2, are thought to be involved in cancer pathogenesis and maintenance of the pluripotency of embryonic stem cells. Fibrillins are important for controlling the growth and differentiation of cells that they surround via interaction with integrins and growth factors as well as regulation of members of the TGF- $\beta$ superfamily. ${ }^{29}$ An FBN-1 deficiency impairs targeting of the large latent complex by the extracellular matrix, resulting in the unrestrained release of TGF- $\beta$ ligands. An elevated TGF- $\beta$ level in patients with MFS is correlated with larger aortic root diameters and faster aortic root growth. ${ }^{30}$ Dysregulated TGF- $\beta 2$ is also associated with vascular EDS. ${ }^{31}$ TGF- $\beta$ actively participates in malignant transformation and progression. Evidence has revealed associations between TGF- $\beta$ and various solid malignancies, including head and neck, ${ }^{32}$ bladder, ${ }^{33}$ prostate, ${ }^{34}$ colon, ${ }^{35}$ lung, ${ }^{36}$ breast, ${ }^{37}$ liver ${ }^{38}$ and renal cell cancer. ${ }^{39}$ Mutations in TGFBR2, a putative tumour 
Table 3 Analysis of malignancy subgroup using conditional logistic regression in a GEE model in patients with or without MFS

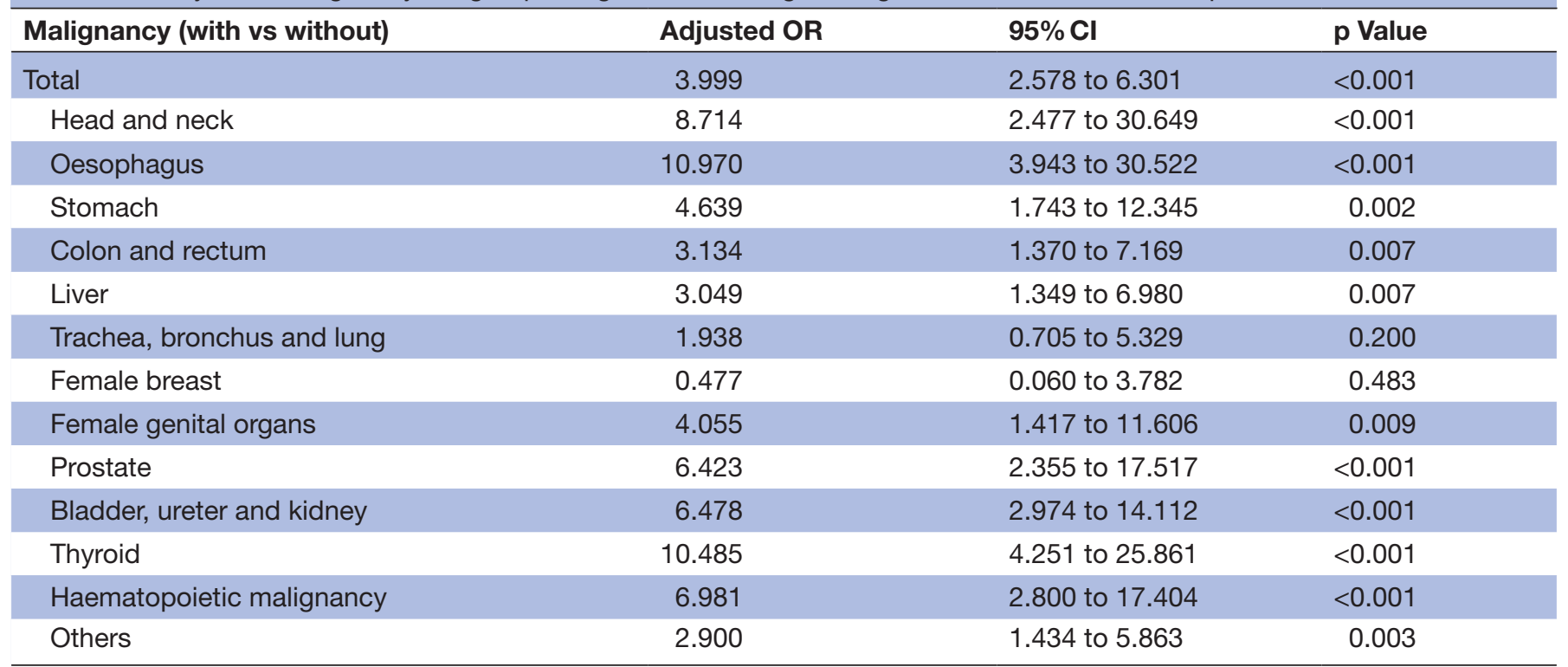

Adjusted OR: adjusted for variables listed in table 2.

GEE, generalised estimating equation; MFS, Marfan syndrome.

suppressor gene implicated in several malignancies, are also associated with inherited connective tissue disorders. ${ }^{40}$ The TGF- $\beta /$ SMAD signalling pathway is constitutively activated in natural killer cells in patients with acute lymphoblastic leukaemia but not in healthy controls. ${ }^{41}$ Functional variants of TGF- $\beta 1$ genes may be significantly associated with the aetiopathogenesis of acute myeloid leukaemia. $^{42}$ TGF- $\beta 1$ also induces the PI3K/Akt/NF- $\mathrm{BB}$ signalling pathway during the recruitment of malignant cells in chronic myeloid leukaemia. ${ }^{43} \mathrm{~A}$ previous study performed in our laboratory has confirmed the association between malignancies and aortic aneurysms (unpublished data).

\section{LIMITATIONS}

The strength of our study is its population-based database design. We identified malignancies using the dual approaches of assessing ICD-9 code records and searching the registry of the Catastrophic Illness Patient Database to increase the accuracy of our data. We excluded

Table 4 Analysis of age and survival regarding malignancy in patients with or without MFS

\begin{tabular}{llll}
\hline MFS & With (\%) & Without (\%) & p Value \\
\hline $\begin{array}{l}\text { Age at first inpatient } \\
\text { visit due to }\end{array}$ & $52.74 \pm 16.92$ & $58.52 \pm 15.29$ & $<0.001$ \\
malignancy & & & \\
$\begin{array}{l}\text { Age at death during } \\
\text { the follow-up period }\end{array}$ & $67.35 \pm 1.63$ & $70.84 \pm 11.85$ & $<0.001$ \\
$\begin{array}{l}\text { Patient mortality } \\
\text { during the follow-up } \\
\text { period }\end{array}$ & $2.15 \%$ & $0.197 \%$ & $<0.001$ \\
\hline
\end{tabular}

MFS, Marfan syndrome. confounding factors of malignancy, including comorbidities. Although we extensively adjusted our results by using multivariate logistic regression models, our study nonetheless exhibited several limitations and did not address certain confounders. First, MFS might be underdiagnosed in Asian populations. ${ }^{44}$ MFS is diagnosed using the Ghent criteria, which are primarily based on clinical features of Caucasian MFS populations; however, clinical features of the cardiovascular, ocular and skeletal systems significantly differ between Caucasian and Asian MFS populations. ${ }^{44-46}$ Second, the NHIRD registry could not provide detailed information regarding laboratory results, family histories and health-related lifestyle factors, such as alcohol consumption or tobacco use, that can increase the risk of malignancy and were potential confounding factors in this study. In our investigation, we also considered COPD incidence as a proxy variable for tobacco use to diminish the potential confounding effect of tobacco use on our results. ${ }^{47}$ Third, this investigation was designed as a casecontrol study because this approach is efficient for relatively rare diseases or diseases with a long latency period, such as MFS, due to cost-related and time-related considerations. Our study can identify associations between MFS and malignancies, but a case-control study cannot prove a cause-effect relationship. Ethnic differences in the association between MFS and malignancy should be further explored in larger, international, prospective follow-up studies enrolling multiple ethnic populations.

\section{CONCLUSIONS}

Patients with MFS are at increased risk of developing various malignancies. Healthcare professionals should be aware of this risk when treating patients with MFS. Relative to other patients, patients with MFS may require additional cancer surveillance. 
Author affiliations

${ }^{1}$ Department of Emergency Medicine, School of Medicine, College of Medicine, Taipei Medical University, Taipei, Taiwan

${ }^{2}$ Department of Emergency and Critical Medicine, Wan Fang Hospital, Taipei Medical University, Taipei, Taiwan

${ }^{3}$ Department of Emergency Medicine, Tri-Service General Hospital, National Defense Medical Center, Taipei, Taiwan

${ }^{4}$ Institute of Clinical Medicine, National Yang-Ming University, Taipei, Taiwan

${ }^{5}$ Department of Medical Research, Tri-Service General Hospital, National Defense

Medical Center, Taipei, Taiwan

${ }^{6}$ School of Public Health, National Defense Medical Center, Taipei, Taiwan

${ }^{7}$ Taiwanese Injury Prevention and Safety Promotion Association, Taoyuan, Taiwan

${ }^{8}$ Department of Pediatrics, Taoyuan Armed Forces General Hospital, Taoyuan, Taiwan

Contributors C-WH and M-TL conceptualised and designed the study. J-CW, W-IL and $\mathrm{S}-\mathrm{HT}$ reviewed relevant literature and drafted the manuscript. W-CC provided the dataset and coordinated the study. C-HC, C-HT and Y-FW analysed the data. All authors collected and interpreted the data and approved the manuscript.

Funding This study was supported by grants from the Tri-Service General Hospital, National Defense Medical Center, Taipei, Taiwan (TSGH-C106-002 and TSGHC106-048); Taoyuan Armed Forces General Hospital, Taoyuan, Taiwan (10514) and Ministry of Science and Technology (MOST 106-2314-B-016-031-

Competing interests None declared.

Provenance and peer review Not commissioned; externally peer reviewed.

Data sharing statement № additional data are available.

Open Access This is an Open Access article distributed in accordance with the terms of the Creative Commons Attribution (CC BY 4.0) license, which permits others to distribute, remix, adapt and build upon this work, for commercial use, provided the original work is properly cited. See: http://creativecommons.org/ licenses/by/4.0/

(C) Article author(s) (or their employer(s) unless otherwise stated in the text of the article) 2017. All rights reserved. No commercial use is permitted unless otherwise expressly granted.

\section{REFERENCES}

1. Halushka MK, Angelini A, Bartoloni G, et al. Consensus statement on surgical pathology of the aorta from the Society for Cardiovascular Pathology and the Association For European Cardiovascular Pathology: II. Noninflammatory degenerative diseases - nomenclature and diagnostic criteria. Cardiovasc Pathol 2016;25:247-57.

2. Cook JR, Carta L, Galatioto J, et al. Cardiovascular manifestations in Marfan syndrome and related diseases; multiple genes causing similar phenotypes. Clin Genet 2015;87:11-20.

3. Kubiczkova L, Sedlarikova L, Hajek R, et al. TGF- $\beta$-an excellent servant but a bad master. J Transl Med 2012;10:183.

4. Katsuno Y, Lamouille S, Derynck R. TGF- $\beta$ signaling and epithelialmesenchymal transition in cancer progression. Curr Opin Oncol 2013;25:76-84.

5. Corso A, Pagnucco G, Morra E, et al. [The diagnosis of nonHodgkin's lymphoma in a patient with Marfan's syndrome]. Minerva Med 1993;84:417-9.

6. Sharief N, Kingston JE, Wright VM, et al. Acute leukemia in an infant with Marfan's syndrome: a case report. Pediatr Hematol Oncol 1991:8:323-7.

7. Miyajima $\mathrm{Y}$, Kitase $\mathrm{Y}$, Mizuno S, et al. [Acute lymphoblastic leukemia in a pediatric patient with Marfan's syndrome]. Rinsho Ketsueki 2011;52:28-31.

8. Winer DA, Winer S, Rotstein L, et al. Villous papillary thyroid carcinoma: a variant associated with marfan syndrome. Endocr Pathol 2012;23:254-9.

9. Roopnariane A, Freed RJ, Price S, et al. Osteosarcoma in a Marfan patient with a novel premature termination codon in the FBN1 gene. Connect Tissue Res 2011;52:157-65.

10. Yoshitake $\mathrm{K}$, Hagiwara $\mathrm{Y}$, Tanae $\mathrm{K}$, et al. [Marfan syndrome complicated with CD5+ CD10+ diffuse large B-cell lymphoma]. Rinsho Ketsueki 2010;51:196-200.

11. Lachanas $\mathrm{E}$, Tomos $\mathrm{P}$, Fotinou $\mathrm{M}$, et al. Lymphoma presenting as chronic aortic dissection in Marfan syndrome. Ann Hematol 2006;85:181-2.

12. Kraemer DM, Waschke J, Kunzmann V, et al. Veno-occlusive disease in a male patient with Marfan syndrome and common acute lymphoblastic leukemia during induction therapy. Ann Hematol 2003;82:444-7.

13. Lee JJ, Kim HJ, Chung IJ, et al. A case of Marfan syndrome with acute monoblastic leukemia. Korean J Intern Med 1998:13:140-2.

14. Bisconti M, Bisetti A, Bidoli P. Malignant mesothelioma in subjects with Marfan's syndrome and Ehlers-Danlos syndrome: only an apparent association? Respiration 2000;67:223-8.

15. Togashi Y, Sakoda H, Sugahara H, et al. [Loeys-Dietz syndrome with acute myeloid leukemia]. Rinsho Ketsueki 2008;49:664-7.

16. Cheng CL, Kao YH, Lin SJ, et al. Validation of the National Health Insurance Research Database with ischemic stroke cases in Taiwan. Pharmacoepidemiol Drug Saf 2011;20:236-42.

17. Mao CT, Tsai ML, Wang CY, et al. Outcomes and characteristics of patients undergoing percutaneous angioplasty followed by belowknee or above-knee amputation for peripheral artery disease. PLoS One 2014;9:e111130.

18. Lee LJ, Chang YY, Liou SH, et al. Estimation of benefit of prevention of occupational cancer for comparative risk assessment: methods and examples. Occup Environ Med 2012;69:582-6.

19. Wu CY, Chan FK, Wu MS, et al. Histamine2-receptor antagonists are an alternative to proton pump inhibitor in patients receiving clopidogrel. Gastroenterology 2010;139:1165-71.

20. Milleron O, Arnoult F, Ropers J, et al. Marfan Sartan: a randomized, double-blind, placebo-controlled trial. Eur Heart J 2015;36:2160-6.

21. Okada M, Takeuchi E, Mori Y, et al. An autopsy case of angiosarcoma arising around a woven Dacron prosthesis after a Cabrol operation. $J$ Thorac Cardiovasc Surg 2004;127:1843-5.

22. Dexeus FH, Logothetis CJ, Chong C, et al. Genetic abnormalities in men with germ cell tumors. J Urol 1988;140:80-4.

23. Newbold SG, Shafer AD, Goodwin CD, et al. Stage III Wilms' tumor of a solitary kidney in a patient with Marfan's syndrome: a 5-yr survival. J Pediatr Surg 1982:17:841-2.

24. Fassbender WJ, Krohn-Grimberghe B, Görtz B, et al. Multiple endocrine neoplasia (MEN)-an overview and case report-patient with sporadic bilateral pheochromocytoma, hyperparathyroidism and marfanoid habitus. Anticancer Res 2000;20:4877-87.

25. Sotos JG. Abraham Lincoln's marfanoid mother: the earliest known case of multiple endocrine neoplasia type 2B? Clin Dysmorphol 2012;21:131-6.

26. Papadopoulos A, Ntaios G, Kaiafa G, et al. Veno-occlusive disease of the liver during induction therapy for acute lymphoblastic leukemia. Int $\mathrm{J} \mathrm{Hematol}$ 2008;88:441-2.

27. Bell $D$, Marshman D. Diffuse large B cell lymphoma in a prosthetic aortic graft. Heart, Lung and Circulation 2017;26:e4-e6.

28. Ghosh S, Ghosh S, Kumar Ghosh S. Aortic aneurysm and nonHodgkin's lymphoma in Marfan syndrome. Turk J Haematol 2009;26:31-3.

29. Davis MR, Andersson R, Severin J, et al. Transcriptional profiling of the human fibrillin/LTBP gene family, key regulators of mesenchymal cell functions. Mol Genet Metab 2014:112:73-83.

30. Franken R, den Hartog AW, de Waard V, et al. Circulating transforming growth factor- $\beta$ as a prognostic biomarker in Marfan syndrome. Int J Cardiol 2013;168:2441-6.

31. Morissette R, Schoenhoff F, Xu Z, et al. Transforming growth factor- $\beta$ and inflammation in vascular (type IV) Ehlers-Danlos syndrome. Circ Cardiovasc Genet 2014;7:80-8.

32. Liu JF, Mao L, Bu LL, et al. C4.4A as a biomarker of head and neck squamous cell carcinoma and correlated with epithelial mesenchymal transition. Am J Cancer Res 2015;5:3505-15.

33. Liang $\mathrm{Y}$, Zhu F, Zhang $\mathrm{H}$, et al. Conditional ablation of TGF- $\beta$ signaling inhibits tumor progression and invasion in an induced mouse bladder cancer model. Sci Rep 2016;6:29479.

34. Korrodi-Gregório L, Silva JV, Santos-Sousa L, et al. TGF- $\beta$ cascade regulation by PPP1 and its interactors -impact on prostate cancer development and therapy. J Cell Mol Med 2014;18:555-67.

35. Ramamoorthi G, Sivalingam N. Molecular mechanism of TGF- $\beta$ signaling pathway in colon carcinogenesis and status of curcumin as chemopreventive strategy. Tumour Biol 2014;35:7295-305.

36. Jeon HS, Jen J. TGF-beta signaling and the role of inhibitory Smads in non-small cell lung cancer. J Thorac Oncol 2010;5:417-9.

37. Zarzynska JM. Two faces of TGF-beta1 in breast cancer. Mediators Inflamm 2014:2014:1-16.

38. Yoshida K, Murata M, Yamaguchi T, et al. TGF- $\beta /$ Smad signaling during hepatic fibro-carcinogenesis (review). Int J Oncol 2014;45:1363-71.

39. Boström AK, Lindgren D, Johansson ME, et al. Effects of TGF- $\beta$ signaling in clear cell renal cell carcinoma cells. Biochem Biophys Res Commun 2013;435:126-33.

40. Mizuguchi T, Collod-Beroud G, Akiyama T, et al. Heterozygous TGFBR2 mutations in Marfan syndrome. Nat Genet 2004;36:855-60. 
41. Rouce RH, Shaim H, Sekine T, et al. The TGF- $\beta /$ SMAD pathway is an important mechanism for NK cell immune evasion in childhood B-acute lymphoblastic leukemia. Leukemia 2016;30:800-11.

42. Nursal AF, Pehlivan M, Sahin $\mathrm{HH}$, et al. The associations of IL-6, IFN- $\gamma$, TNF- $\alpha$, IL-10, and TGF- $\beta 1$ functional variants with acute myeloid leukemia in Turkish patients. Genet Test Mol Biomarkers 2016;20:544-51.

43. Zhu B, Zhang J, Chen J, et al. Molecular biological characteristics of the recruitment of hematopoietic stem cells from bone marrow niche in chronic myeloid leukemia. Int J Clin Exp Pathol 2015;8:12595-607.
44. Franken R, den Hartog AW, van de Riet L, et al. Clinical features differ substantially between Caucasian and Asian populations of Marfan syndrome. Circ J 2013;77:2793-8.

45. Yoo EH, Woo H, Ki CS, et al. Clinical and genetic analysis of Korean patients with Marfan syndrome: possible ethnic differences in clinical manifestation. Clin Genet 2010;77:177-82.

46. Lim AY, Song JS, Kim EK, et al. Clinical characteristics of Marfan syndrome in Korea. Korean Circ J 2016;46:841-5.

47. Yu TM, Chuang YW, Yu MC, et al. Risk of cancer in patients with polycystic kidney disease: a propensity-score matched analysis of a nationwide, population-based cohort study. Lancet Oncol 2016;17. 